\title{
METÁSTASIS CEREBRAL SOLITARIA DE UN CARCINOMA DE CÉLULAS RENALES
}

\author{
J. HERRERA PUERTO*, J. SOLER FERNÁNDEZ*, S. ASUAR AYDILLO*, \\ C. DOMÍNGUEZ BRAVO*, J. CABEZUDO ALZAR**
}

*Servicio de Urología. **Servicio de Neurocirugía. Hospital Regional Infanta Cristina. Badajoz.

Actas Urol Esp. 27 (6): 468-470, 2003

\section{RESUMEN}

METÁSTASIS CEREBRAL SOLITARIA DE UN CARCINOMA DE CÉLULAS RENALES

La diseminación tumoral a cerebro por una neoplasia renal es un hecho poco habitual, ocurriendo generalmente en estadios muy avanzados, tal como ocurrió en el enfermo comunicado, y lleva asociado un mal pronóstico.

Se trata de una lesión nodular, de moderado tamaño, localizada en el hemisferio izquierdo con síntomas neurológicos acompañantes; el estudio histológico después de la exéresis quirúrgica demostró una metástasis por carcinoma renal.

PALABRAS CLAVE: Tumor. Riñón. Metástasis cerebral.

\section{ABSTRACT \\ SOLITARY BRAIN METASTASIS FROM RENAL CELL CARCINOMA}

The tumour dissemination to brain from renal cell carcinoma is a rare occurrence; generally, it's seen in advanced stages of the disease, such that occurred in our patient that indicated a poor prognosis.

A lesion node, the size medle, located in the side left to brain, with of symptoms neurologic associated was found. Histological examination of the resection specimen revealed metastasis from a renal cell carcinoma.

KEY WORDS: Tumor. Kidney. Brain metastasis.

$\mathrm{E}^{1}$ carcinoma renal supone el $2-3 \%$ de todos los tumores malignos del adulto ${ }^{1}$, y en el momento del diagnóstico un 25-33\% de los pacientes ya tienen metástasis ${ }^{2}$.

El lugar más habitual de diseminación hematógena a distancia es el pulmón, hígado y hueso $^{2}$; la enfermedad metastásica en el sistema nervioso central ocurre entre el 5-10\% de los tumores renales pero la afectación solitaria cerebral representa una incidencia del 0,6$2,5 \%{ }^{3}$, presagiando un pronóstico desfavora$\mathrm{ble}^{4}$.
Se aporta un nuevo caso a la literatura, haciéndose una puesta a punto bibliográfica de esta manifestación por cáncer renal.

\section{CASO CLÍNICO}

Mujer de 67 años, con antecedentes de hipertensión y nefrectomia total izda por hipernefroma (pT3NoMo) (Fig. 1) 9 meses antes, que ingresa en el servicio de neurocirugía por crisis clónicas en extremidad superior y párpado de ojo derechos junto a dificultad para mover el miembro inferior derecho (M.I.D.) de varios semanas de evolución. 


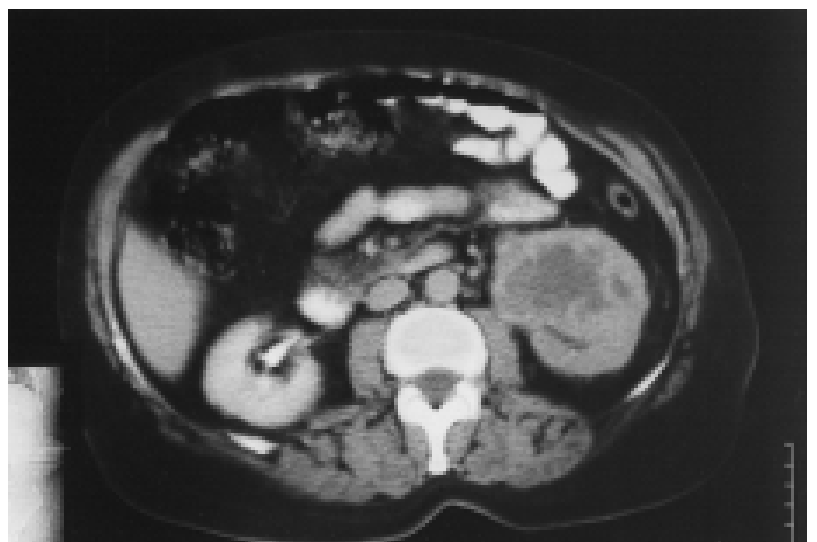

FIGURA 1. Imagen de TAC abdominal con tumoración renal izquierda.

A la exploración se encontraba consciente y orientada. Normotensa. Hemiparesia derecha braquiocrural e hiperreflexia en miembro inferior homolateral. Sensibilidad, pares craneales y fondo de ojo normales. Ausencia de adenovisceromegalias. Cicatriz de incisión subcostal izquierda. Puñopercusión renal derecha negativa y normal volumen urinario.

Analítica general, hemoglobina, coagulación, enzimas hepáticos, F. Alcalina y CEA, normales. Orina de Ph neutro.

Practicado TAC craneal de urgencia se objetivó una tumoración, única, subcortical en lóbulo parietal izquierdo de $1,5 \mathrm{cms}$, hipercaptante e intenso edema perilesional (Fig. 2). Se completó estudio (Scanner, gammagrafia ósea,...) sin apreciarse otros hallazgos patológicos.

Con el diagnóstico de proceso expansivo cerebral solitario se efectuó extirpación de la lesión mediante craneotomia asistida con el sistema de estereotaxia, informando el examen histológico de metástasis por adenocarcinoma renal (Fig. 3). Fue remitida a la unidad de Oncología indicándose radioterapía craneal externa focal (50 Gy) complementaria.

La evolución inmediata fue satisfactoria aunque persistió la hemiparesia en M.I.D. que precisó rehabilitación. Después de 14 meses de seguimiento, la paciente causó éxitus tras deterioro del estado general y estado preagónico por metástasis múltiples.

\section{DISCUSIÓN}

La historia natural del adenocarcinoma renal es poco previsible, y la expresión del tumor pri-

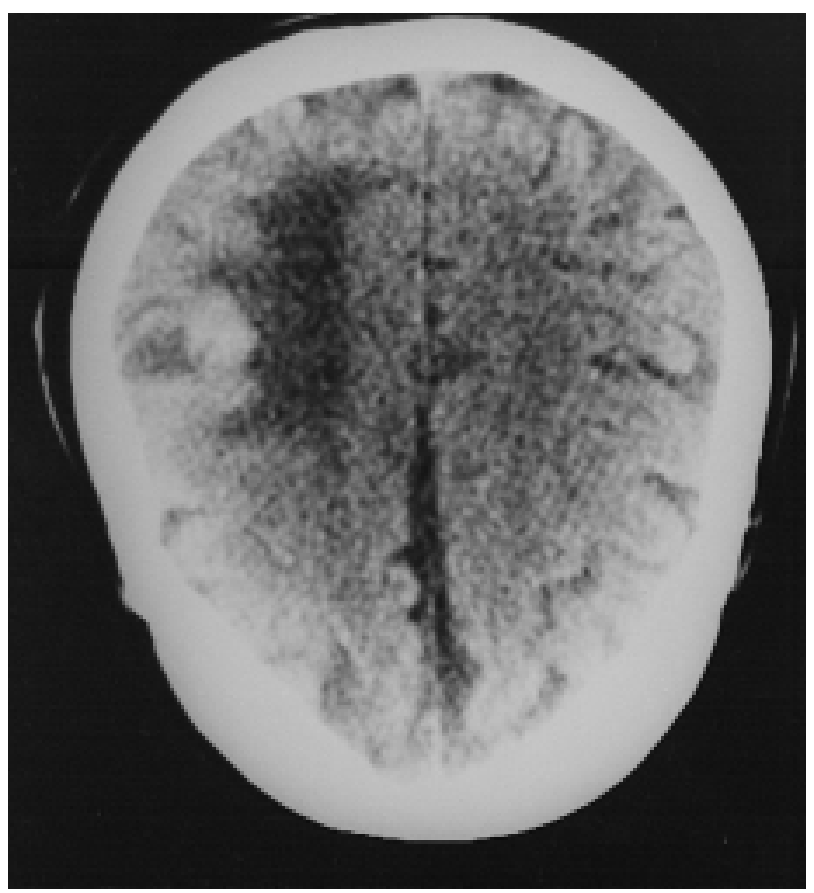

FIGURA 2. TAC craneal: tumoración parietal izquierda y edema perilesional.

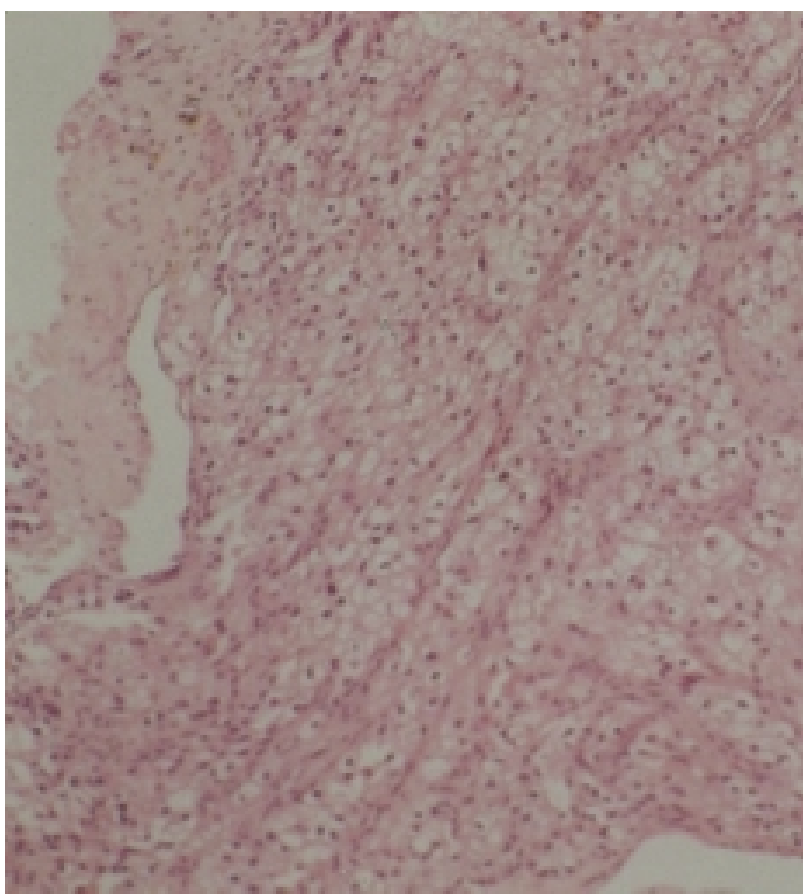

FIGURA 3. Examen histológico: neoplasia epitelial malig na de células claras correspondiente a metástasis por cáncer renal. HE 40x.

mitivo y sus metástasis es manifestada de formas muy diversas, tendiendo a la diseminación neoplásica en un plazo que varía de semanas a $\operatorname{años}^{2}$. 
Según Delarive ${ }^{5}$, el tumor que más frecuentemente metastatiza el cerebro es el bronquial, seguido por el melanoma, mama, intestino o desconocidos. Del total de metástasis intracraneales, alrededor del $10 \%$ tienen una localización renal aconteciendo en el curso de la enfermedad generalizada, siendo la presentación aislada un hecho poco usual ${ }^{6}$, igual que aconteció en el caso informado.

Clínicamente, la mayoria de pacientes manifiestan sintomas focales deficitarios, trastornos neuropsiquiátricos, crisis convulsivas o mareos y cefaleas por hipertensión intracraneal ${ }^{7}$.

El diagnóstico de metástasis cerebral se lleva a cabo por exclusión, si bien un enfermo con antecedentes de nefrectomía por tumor la sospecha inmediata es una metástasis metacrónica; la $\mathrm{TAC}$, habitualmente realizada de urgencia, informa de las características de la lesión, pero no existen patrones radiográficos patognomónicos sobre la naturaleza neoplásica de las mismas, por lo que su confirmación se impone mediante biopsia o examen histológico de la pieza de exéresis ${ }^{8}$.

Si bien no existe criterio unánime respecto al tratamiento ideal del cáncer renal metastásico de cerebro, en el caso de una metástasis solitaria la exéresis quirúrgica asegurando margen sano complementada con radioterapia del lecho tumoral, para disminuir las posibilidades de recidiva, parece ser la opción terapéutica más adecuada ${ }^{9-11}$. Algunos autores sugieren, en pacientes seleccionados con buen status performance, la combinación de tumurectomía craneal y tratamiento inmune con interferon alfa obteniendo resultados prometedores, pero se precisan largas series para conocer sus efectos definitivos ${ }^{12,13}$.

A pesar del mal significado pronóstico que supone la diseminación neoplásica a cerebro por cáncer renal ${ }^{4}$, la supervivencia es mejor cuanto mayor sea el tiempo transcurrido entre el diagnóstico del tumor primario y la metástasis metacrónica $^{14}$.

\section{REFERENCIAS}

1. DeKERNION BJ, BELLDEGRUM A.: Renal tumors. In: Campbell's Urology. Eds. Walsh PC, Retik AB, Vaughan ED, and Wein AS. Seventh Edition. Philadephia. Saunders Company 1998; 3: 2283-2326.

2. BEDOS F, CIBERT J.: Tumores del parénquima renal. En: Urología. La terapéutica y sus bases. Barcelona. Espaxs Publicaciones Médicas 1989: 303387.

3. JUBELIRER SJ.: Late solitary cerebral mestastasis from renal cell carcinoma: a case report and review of the literature. WV Med $J$ 1996; 92: 26-27.

4. ROSER F, ROSAHL SK, SAMII M.: Single cerebral metastasis 3 and 19 years after primary renal cell carcinoma: case report and review of the literature. $J$ Neurol Neurosurg Psychiatry 2002; 72: 257-258.

5. DELARIVE J, TRIBOLET N.: Métastases cerébrales. Etude d'un collectif chirurgical de 81 cas. Neurochirurgie 1992; 38: 89-97.

6. SOUSA ESCANDÓN MA, CHANTADA AVAL V, ANTÓN APARICIO LM. y cols.: Metástasis cerebelosa solitaria: un ejercicio diagnóstico. Act Esp Urol 1999; 5: 459463.

7. N`DRI-OKA D, DEKOU A et al.: Epilepsy disclosing cancer of the kidney. Ann Urol 1999; 33: 48-50.

8. WRONSKI M, ARBIT E, RUSSO P, GALICICH JH.: Surgical resection of brain metastasis from renal cell carcinoma in 50 patients. Urology 1996; 47: 187-193.

9. BADALAMENT RA, GLUCK RW, FAIR HW, GALICICH JH.: Surgical treatment of brain metastasis from renal cell carcinoma. Urology 1990; 36: 112-117.

10. HARADA Y, NONOMURA N et al.: Clinical study of brain metastasis of renal cell carcinoma. Eur Urol 1999; 36: 230-235.

11. KUROKI K, TAGUCHI $\mathrm{H}$ et al.: Cerebral metastasis from a renal cell carcinoma more than 10 years after nephrectomy: report of tow cases. No Shinkei Geka 1999; 27: 89-93.

12. YAMANAKA K, GOHJI K, GOTOH A et al.: Clinical study of renal cell carcinoma with brain metastasis. Int $J$ Urol 1998; 5: 124-128.

13. SIMONOVA G, LISCAK R, NOVOTNY J.: Solitary brain metastases treat with the Leksell gamma knike: prognosis factors for patients. Radiother Oncol 2000; 57: 207-211.

14. MANI S, TODD MR, POO W.: Prognostic factors for survival in patients with metasytatic renal cancer treated with biological reponse modifiers. J Urol 1995; 154: $35-40$.

Dr. J. Herrera Puerto

C/ Bolivar, 24 - 3ํ C

37004 Salamanca

(Trabajo recibido el 2 diciembre de 2002) 